\title{
Spodick's Sign: A Case Report and Review of Literature
}

\author{
Basel Abdelazeem ${ }^{1}$, Emad Kandah ${ }^{1}$, Mariem Borcheni ${ }^{2}$, Saed Alnaimat ${ }^{3}$, Arvind Kunadi $^{1}$ \\ 1. Internal Medicine, McLaren Health Care, McLaren Flint, Michigan State University, Michigan, USA 2. Internal \\ Medicine, Sfax Faculty of Medicine, Sfax, TUN 3. Cardiology, McLaren Health Care, McLaren Flint, Michigan State \\ University, Michigan, USA
}

Corresponding author: Basel Abdelazeem, basel.abdelazeem@mclaren.org

\begin{abstract}
Acute pericarditis is commonly diagnosed in patients who present with chest pain. Accurate diagnosis of acute pericarditis is essential because of its relative similarity to ST-elevation myocardial infarction (STEMI) in both clinical presentation and electrocardiogram (EKG) changes. Additionally, troponin elevation is occasionally seen in acute pericarditis due to myocardial involvement (myopericarditis), which makes accurate diagnosis more challenging. A 12-lead EKG remains the most useful diagnostic test in differentiating acute pericarditis from STEMI. Spodick's sign is a less recognized electrocardiographic feature of acute pericarditis and is frequently overlooked by clinicians. We present a case of a 52-year-old male who initially presented with acute onset substernal chest pain. His EKG revealed diffuse subtle ST elevation and downsloping TP segment (Spodick's sign). A coronary angiogram demonstrated normal coronaries which eliminated the possibility of coronary artery disease. In this article, we will discuss how to differentiate between acute pericarditis and myocardial infarction, with a focus on Spodick's sign, amongst other EKG findings suggestive of pericarditis.
\end{abstract}

Review began 10/20/2020 Review ended 11/09/2020 Published 11/21/2020

\section{(๑) Copyright 2020}

Abdelazeem et al. This is an open access article distributed under the terms of the Creative Commons Attribution License CC-BY 4.0., which permits unrestricted use, distribution, and reproduction in any medium, provided the original author and source are credited.
Categories: Cardiology, Family/General Practice, Internal Medicine

Keywords: spodick's sign, acute pericarditis, case report, stemi

\section{Introduction}

The pericardium is a double-walled, thin, avascular sac that has two layers; an outer fibrous layer and an inner serous layer. The pericardial cavity normally contains about 30 to $50 \mathrm{ml}$ of plasma ultra-filtrate, which acts as a lubricant to reduce friction within the prericardium, and to provide mechanical protection for the heart [1]. Acute pericarditis is an inflammatory condition of the pericardium that could be caused by infectious or noninfectious etiologies [2]. Pericarditis is classified as acute ( $<3$ months), recurrent (repeated episodes of acute pericarditis), or chronic ( $>3$ months) in duration [3]. Acute and recurrent pericarditis are relatively common in clinical practice. Approximately $30 \%$ of patients who develop acute pericarditis develop recurrence after the initial episode [4]. Clinical presentation can vary considerably, ranging from asymptomatic to life-threatening. Patients classically present with pleuritic chest pain that is alleviated by leaning forward. On examination, pericardial friction rub may be heard. Pericarditis has four stages on electrocardiogram (EKG) based on ST and T wave changes [3]. Spodick's sign refers to a downsloping TP segment, best visualized in lead II and lateral precordial leads [5]. It was first described by Dr. David Spodick in 1974 , and is found in about $29 \%$ of patients with acute pericarditis. It represents an important clue in differentiating acute pericarditis from ST-elevation myocardial infarction (STEMI) [2-3].

\section{Case Presentation}

A 52-year-old African American male with a past medical history of hypertension, asthma, chronic kidney disease stage-3, and obesity, presented with acute onset retrosternal chest pain for two-day duration; the pain was intermittent, mild 2/10 in severity, and worsened with exertion and inspiration. On physical exam, the patient was afebrile, with regular heart rate and rhythm. Auscultation revealed normal S1 and S2 without any cardiac murmurs or pericardial friction rub. His EKG revealed diffuse, subtle ST elevation in addition to Spodick's sign (Figure 1). He denied any recent fever, chills, sore throat, or viral symptoms. Laboratory studies were significant for elevated erythrocyte sedimentation rate (ESR), elevated C-reactive protein, and a normal troponin-I (Table 1). Routine chest X-ray demonstrated mild cardiomegaly (Figure 2). Echocardiography revealed a left ventricular ejection fraction of $70 \%$ and a trivial pericardial effusion (Videos 1-2). Coronary angiogram revealed normal coronary arteries (Videos 3-4). The patient was started on treatment for pericarditis with renally dosed colchicine and aspirin. He reported improvement of his symptoms on subsequent outpatient follow up. 


\section{Cureus}

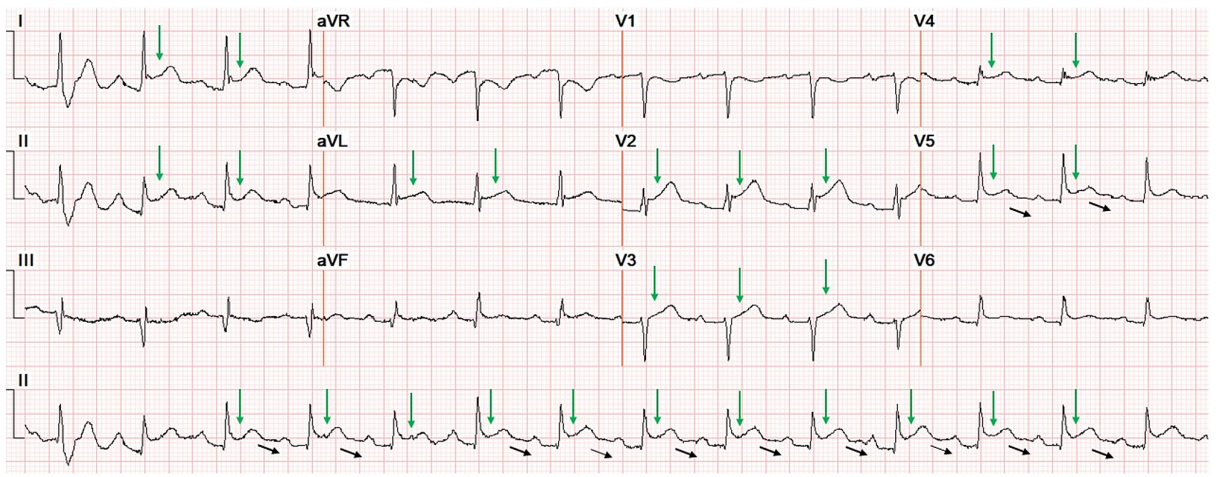

FIGURE 1: Diffuse ST elevation (green arrow) and downsloping TP segment (black arrows)

Basic Metabolic panel

Glucose 127 H (70-105 mg/dL)

BUN 21(7-22 mg/dL)

Creatinine $2.30 \mathrm{H}(0.50-1.50 \mathrm{mg} / \mathrm{dL})$

eGFR African American 36 L(60-200 mL/min)

BUN/Creatinine Ratio 9.1 L(12.0-20.0)

Calcium $8.5(8.5-10.5 \mathrm{mg} / \mathrm{dL})$

Sodium 138(134-145 mM/L)

Potassium 3.1 L(3.5-5.1 mM/L)

Chloride 98(98-112 mM/L)

Carbon Dioxide 27(24-30 mM/L)

Anion Gap 13.0(6.0-14.0 mM/L)

C Reactive Protein $\quad 19.1 \mathrm{H}(0.0-0.9 \mathrm{mg} / \mathrm{dL})$
Complete blood count

$\begin{array}{ll}\text { WBC Count } & 11.44 \mathrm{H}\left(4.50-11.00 \times 10^{*} 3 / \mathrm{uL}\right) \\ \text { RBC Count } & 3.65 \mathrm{~L}\left(4.70-6.10 \times 10^{\star} 6 / \mathrm{uL}\right) \\ \text { Hemoglobin } & 10.6 \mathrm{~L}(13.5-17.7 \mathrm{~g} / \mathrm{dL})\end{array}$
$\begin{array}{ll}\text { Hemoglobin } & 10.6 \mathrm{~L}(13.5-17.7 \mathrm{~g} / \mathrm{dL})\end{array}$
$\begin{aligned} & \text { Platelet Count } \\ & 271\left(140-440 \times 10^{\star} 3 / \mathrm{uL}\right)\end{aligned}$
Neutrophils, Automated $\quad 69.5(\%)$
Lymphocytes, Automated $\quad 15.0(\%)$

Lymphocytes, Automated $\quad 15.0(\%)$

Sedimentation Rate Westergren $60 \mathrm{H}(0-20 \mathrm{~mm} / \mathrm{Hr})$

\section{TABLE 1: Laboratory workup}

WBC: white blood cells; RBC: red blood cells; BUN: blood urea nitrogen; eGFR: estimated glomerular filtration rate. 


\section{Cureus}

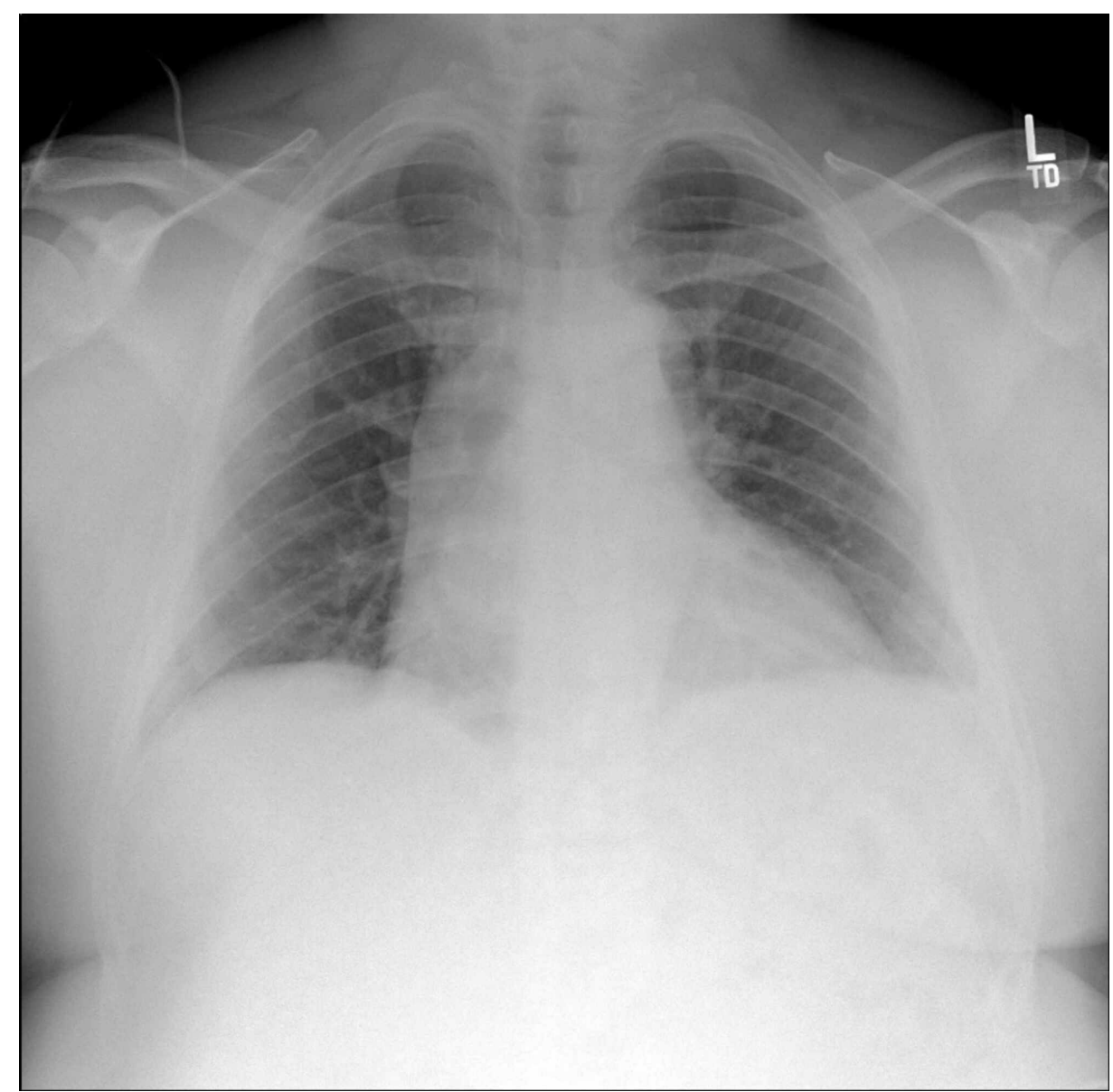

FIGURE 2: Chest X-ray showed mild cardiomegaly

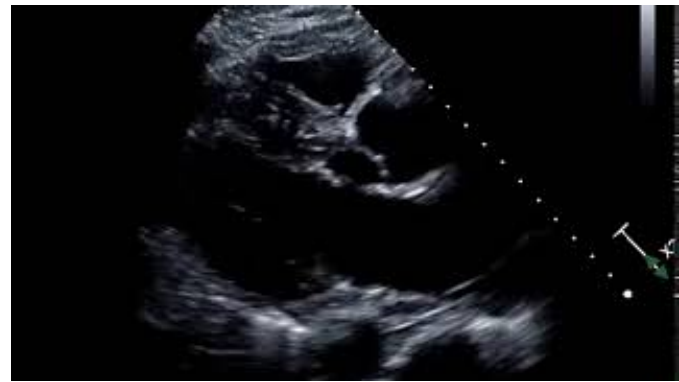

VIDEO 1: Echocardiogram revealed a left ventricular ejection fraction of $70 \%$ and a trivial pericardial effusion

View video here: https://youtu.be/1Ayg8zHjEOI

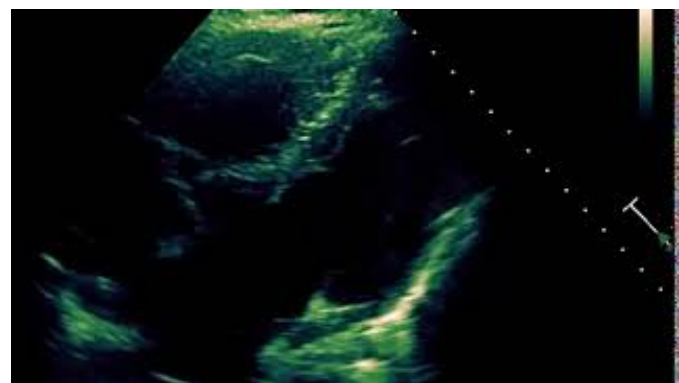

VIDEO 2: Echocardiogram revealed a left ventricular ejection fraction of 


\section{Cureus}

\section{$70 \%$ and a trivial pericardial effusion}

View video here: https://youtu.be/Pu-L6zM-iLA

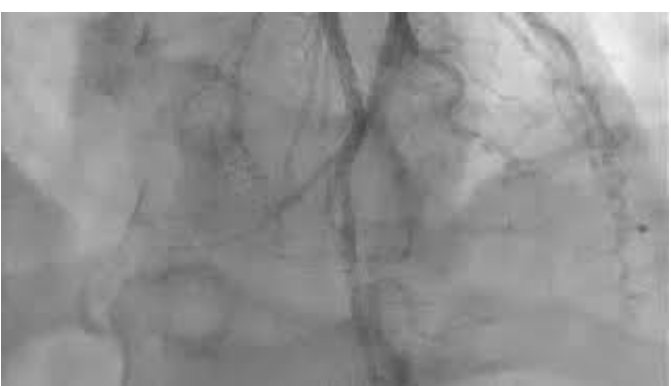

VIDEO 3: Coronary angiogram showed normal coronary arteries

View video here: https://youtu.be/qVwgx6Aftmo

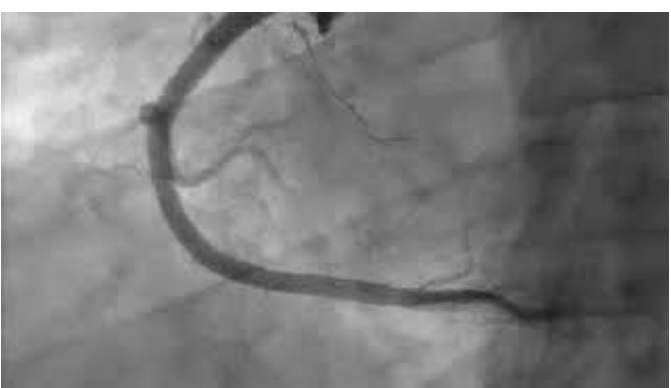

VIDEO 4: Coronary angiogram showed normal coronary arteries

View video here: https://youtu.be/DNP_IWud_n0

\section{Discussion}

Acute pericarditis is diagnosed in about $0.1 \%$ of hospitalized patients and $5 \%$ of patients presenting to the emergency department with chest pain after ischemic causes were ruled out [6]. The majority of diagnosed cases (up to 75\%) are idiopathic [7]. Infectious etiologies include viral infections (e.g. Coxsackie virus, which is the most common infectious etiology); tuberculosis, which is a common cause of pericarditis in developing countries [3]; and other bacterial or fungal infections. Post myocardial infarction pericarditis can occur early (within two to four days) in up to $25 \%$ of patients, or late as Dressler syndrome, in which autoimmune pericarditis occurs weeks to months after myocardial infarction [8]. Neoplastic etiologies also should be considered and include primary tumor of the pericardium such as mesothelioma and sarcoma, metastatic spread, or direct invasion from a nearby lung/breast cancer or lymphoma [9]. Other causes to consider may include metabolic disorders (such as uremia, hypothyroidism), autoimmune connective tissue diseases (such as rheumatic fever, systemic lupus erythematosus, and rheumatoid arthritis [10]). Additionally, pericarditis can be traumatic secondary to cardiothoracic surgeries or chest trauma [11].

Most cases present with pleuritic chest pain, substernal or left-sided, severe, sharp that increases with inspiration and improves with leaning forward [12]. Occasionally, patients may report a prodrome of fever, malaise, and myalgia. On physical examination, patients may have tachycardia and pericardial friction rub (due to friction between the two inflamed pericardial layers) [13].

EKG plays a major role in diagnosing acute pericarditis. However, EKG features can be seen in no more than $60 \%$ of the cases. Although the pericardial sac itself lacks electrical activity, inflammation of the pericardium can disrupt the action potential in the adjacent myocardium (epicardium), leading to characteristic ST segment elevation on EKG. A local insult to myocardial cells can result in distortion of the shape of action potential, causing a voltage gradient (current of injury) between injured myocardial cells and surrounding unaffected cells. This current of injury is reflected in ST segments on vectors pointing towards a lesion, leading to ST segments elevation or depression with variable morphologies. Generally, ST segment elevation occurs in transmural or epicardial injury, whereas ST segment depression occurs if subendocardial insult is present. Due to the diffuse nature of pericardial inflammation, the current of injury does not correspond to a specific coronary territory as seen in cases of STEMI. Involvement of the atria is responsible for PR segment depression and is quite specific for pericarditis [14]. 


\section{Cureus}

summarized in Table 2. The suggestive findings of acute pericarditis are summarized in Table 3 . These changes may not be present in every patient with acute pericarditis. Important electrocardiographic clues in differentiating acute pericarditis from myocardial infarction are summarized in Table 4 [15-18].

\begin{tabular}{|c|c|c|c|c|}
\hline Stages & stage I & stage II & stage III & stage IV \\
\hline $\begin{array}{l}\text { IIme } \\
\text { frame }\end{array}$ & Hours to several days & $\begin{array}{l}\text { A tew days to } \\
\text { weeks }\end{array}$ & Several weeks & Months \\
\hline \multirow{4}{*}{$\begin{array}{l}\text { EKG } \\
\text { findings }\end{array}$} & $\begin{array}{l}\text { PR-segment depression, except in } \\
\text { aVR }\end{array}$ & $\begin{array}{l}\text { Normalization of } \\
\text { ST and PR } \\
\text { segments }\end{array}$ & \multirow{4}{*}{$\begin{array}{l}\text { T-wave inversion } \\
\text { persists with isoelectric } \\
\text { ST- segments }\end{array}$} & $\begin{array}{l}\text { Gradual resolution of I-wave } \\
\text { inversion }\end{array}$ \\
\hline & PR segment elevation in lead aVR & \multirow{3}{*}{$\begin{array}{l}\text { T waves } \\
\text { progressively } \\
\text { flatten and invert. }\end{array}$} & & \multirow{3}{*}{$\begin{array}{l}\text { Diffuse ST-segment depression and } \\
\text { T-wave inversion may persist up to } 3 \\
\text { months. }\end{array}$} \\
\hline & $\begin{array}{l}\text { Diffuse concave-upward ST- } \\
\text { segment elevation with concordant } \\
\text { (upright) T waves } \\
\text { Absence of reciprocal ST-segment } \\
\text { changes }\end{array}$ & & & \\
\hline & $\begin{array}{l}\text { Leads aVR and V1 may have ST- } \\
\text { segment depression }\end{array}$ & & & \\
\hline
\end{tabular}

TABLE 2: EKG findings consistent with pericarditis in the different chronological stages

EKG findings suggestive of acute pericarditis

ST-elevation is less than $5 \mathrm{~mm}$

ST-segment concavity

More extensive lead involvement

Less prominent reciprocal ST-segment depression

PR-segment elevation in aVR, with reciprocal PR-segment depression in other leads

The absence of abnormal Q-waves

Variability in the time of T-wave inversion occurrence following ST-segment elevation

The lack of QRS widening and QT interval shortening in leads with ST-elevation

TABLE 3: EKG findings suggestive of acute pericarditis

\begin{tabular}{|c|c|}
\hline Acute pericarditis & Myocardial infarction \\
\hline $\begin{array}{l}\text { ST-segment elevation usually "concave" upward (bulge } \\
\text { downward) }\end{array}$ & $\begin{array}{l}\text { ST-segment elevation usually "convex" downward (bulge upward) during } \\
\text { acute injury }\end{array}$ \\
\hline Diffuse ST elevation & ST-elevation related to location of ischemia \\
\hline No $Q$ waves or reciprocal changes are seen & Q waves often appear \\
\hline PR-segment depression often occurs & No PR-segment depression \\
\hline
\end{tabular}

TABLE 4: Comparison of EKG findings in acute pericarditis and myocardial infarction 
between STEMI and pericarditis. Spodick's sign is a downsloping of the TP segment mainly seen in lead II and lateral precordial leads [5].

According to the European Society of Cardiology, acute pericarditis requires the presence of two or more of the following: pericarditic chest pain, pericardial friction rub, new widespread ST-segment elevation or PR depression, or new or worsening pericardial effusion [9]. Our patient presented with chest pain and diffuse ST segment elevation on EKG, and echocardiography revealed a trivial pericardial effusion meeting the diagnostic criteria for acute pericarditis.

In a recently published retrospective study that included 165 patients with STEMI and 42 patients with pericarditis, Spodick's sign was noticed in 5\% of patients with STEMI (95\% CI 3\%-10\%) and 29\% of patients with pericarditis ( $95 \%$ CI 16\%-45\%). No single EKG sign was pathognomonic for STEMI or pericarditis. Up to $12 \%$ of patients with STEMI had PR segment depression. This data was collected from a single site and has a small number of pericarditis patients, limiting the accuracy of results and generalizability of findings. Further studies are needed to validate these results [16].

Echocardiography is helpful in assessing cardiac function and presence of pericardial effusion [19]. ESR and C-reactive protein are markers of inflammation and are frequently elevated in patients with acute pericarditis. Troponin elevation is seen in patients with myocardial involvement (myopericarditis). The most common complications of acute pericarditis are pericardial effusion and cardiac tamponade. Up to $60 \%$ to $75 \%$ of patients with acute pericarditis may develop pericardial effusion $[7,9,13,18]$.

\section{Conclusions}

EKG remains the most useful diagnostic test in differentiating acute pericarditis from STEMI. Among several EKG findings that may suggest pericarditis, Spodick's sign is an important diagnostic clue that is commonly overlooked by clinicians. However, Spodick's sign is not pathognomonic for acute pericarditis.

\section{Additional Information \\ Disclosures}

Human subjects: Consent was obtained by all participants in this study. Janet Bigelow, Interim privacy officer and cooperative director of compliance program issued approval Not applicable. Informed consent was obtained from the patient. Interim privacy officer and cooperative director of compliance program at Mclaren Hospital has approved this case report for publication. IRB is not applicable as it is a case report. Conflicts of interest: In compliance with the ICMJE uniform disclosure form, all authors declare the following: Payment/services info: All authors have declared that no financial support was received from any organization for the submitted work. Financial relationships: All authors have declared that they have no financial relationships at present or within the previous three years with any organizations that might have an interest in the submitted work. Other relationships: All authors have declared that there are no other relationships or activities that could appear to have influenced the submitted work.

\section{References}

1. Katinaitė J, Petrauskienė B: Recurrent pericarditis: a case report and literature review . Acta Med Litu. 2017, 24:159-166. 10.6001/actamedica.v24i3.3550

2. Imazio M, Gaita F: Acute and recurrent pericarditis . Cardiol Clin. 2017, 35:505-513. 10.1016/j.ccl.2017.07.004

3. McNamara N, Ibrahim A, Satti Z, Ibrahim M, Kiernan TJ: Acute pericarditis: a review of current diagnostic and management guidelines. Future Cardiol. 2019, 15:119-126. 10.2217/fca-2017-0102

4. Lotrionte M, Biondi-Zoccai G, Imazio M, et al.: International collaborative systematic review of controlled clinical trials on pharmacologic treatments for acute pericarditis and its recurrences. Am Heart J. 2010, 160:662-670. 10.1016/j.ahj.2010.06.015

5. Chaubey VK, Chhabra L: Spodick's sign: a helpful electrocardiographic clue to the diagnosis of acute pericarditis. Perm J. 2014, 18:e122. 10.7812/TPP/14-001

6. Snyder MJ, Bepko J, White M: Acute pericarditis: diagnosis and management. Am Fam Physician. 2014, 89:553-560.

7. Yusuf SW, Hassan SA, Mouhayar E, Negi SI, Banchs J, O'Gara PT: Pericardial disease: a clinical review . Expert Rev Cardiovasc Ther. 2016, 14:525-539. 10.1586/14779072.2016.1134317

8. LeWinter MM: Acute pericarditis. N Engl J Med. 2014, 371:2410-2416. 10.1056/NEJMcp1404070

9. Adler Y, Charron P, Imazio M, et al.: 2015 ESC guidelines for the diagnosis and management of pericardial diseases: the task force for the diagnosis and management of pericardial diseases of the European Society of Cardiology (ESC). Eur Heart J. 2015, 36:2921-2964. 10.1093/eurheartj/ehv318

10. Doctor NS, Shah AB, Coplan N, Kronzon I: Acute pericarditis. Prog Cardiovasc Dis. 2017, 59:349-359. 10.1016/j.pcad.2016.12.001

11. Mugnai G, de Asmundis C, Iacopino S, et al.: Acute pericarditis following second-generation cryoballoon ablation for atrial fibrillation. J Interv Card Electrophysiol. 2018, 51:279-284. 10.1007/s10840-018-0329-z

12. Reamy BV, Williams PM, Odom MR: Pleuritic chest pain: sorting through the differential diagnosis . Am Fam Physician. 2017, 96:306-312.

13. Seferović PM, Ristić AD, Maksimović R, et al.: Pericardial syndromes: an update after the ESC guidelines 


\section{Cureus}

2004. Heart Fail Rev. 2013, 18:255-266. 10.1007/s10741-012-9335-x

14. de Bliek EC: ST elevation: differential diagnosis and caveats. A comprehensive review to help distinguish ST elevation myocardial infarction from nonischemic etiologies of ST elevation. Turkish J Emerg Med. 2018, 18:1-10. 10.1016/j.tjem.2018.01.008

15. Spodick DH: Electrocardiogram in acute pericarditis: distributions of morphologic and axial changes by stages. Am J Cardiol. 1974, 33:470-474. 10.1016/0002-9149(74)90603-1

16. Witting MD, Hu KM, Westreich AA, Tewelde S, Farzad A, Mattu A: Evaluation of Spodick's sign and other electrocardiographic findings as indicators of STEMI and pericarditis. J Emerg Med. 2020, 58:562-569. 10.1016/j.jemermed.2020.01.017

17. Tonini M, de Melo DTP, Fernandes F: Acute pericarditis. Rev Assoc Med Bras. 2015, 61:184-190 10.1590/1806-9282.61.02.184

18. Khandaker MH, Espinosa RE, Nishimura RA, Sinak LJ, Hayes SN, Melduni RM, Oh JK: Pericardial disease: diagnosis and management. Mayo Clin Proc. 2010, 85:572-593. 10.4065/mcp.2010.0046

19. Klein AL, Abbara S, Agler DA, et al.: American Society of Echocardiography clinical recommendations for multimodality cardiovascular imaging of patients with pericardial disease: endorsed by the Society for Cardiovascular Magnetic Resonance and Society of Cardiovascular Computed Tomography. J Am Soc Echocardiogr. 2013, 26:965-1012.e15. 10.1016/j.echo.2013.06.023 